\title{
Improved Component Placement Accuracy with Robotic-Arm Assisted Total Knee Arthroplasty
}

\author{
Ormonde Mahoney, MD ${ }^{1}$ Tracey Kinsey, RN, BSN ${ }^{1} \quad$ Nipun Sodhi, MD 2 Michael A. Mont, MD 3 \\ Antonia F. Chen, MD ${ }^{4}$ Fabio Orozco, MD ${ }^{4}$ William Hozack, MD 4
}

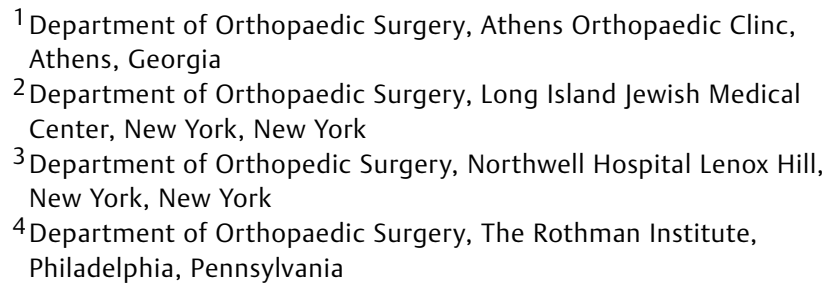

Address for correspondence Michael A. Mont, MD, Department of Orthopaedic Surgery, Northwell Health Orthopaedics, Lenox Hill Hospital, 130 East 77th Street, New York, NY 10075 (e-mail: mmont@northwell.edu).

J Knee Surg 2022;35:337-344.

\begin{abstract}
Keywords

- robotic-arm assisted

- TKA

- component position
\end{abstract}

Component position of total knee arthroplasty (TKA) has been shown to influence prosthetic survivorships and clinical outcomes. Our objective was to compare the three-dimensional accuracy to plan of robotic-arm assisted TKA (RATKA) with conventional TKA for component position. We conducted a nonrandomized, prospective study comparing 143 RATKA with 86 conventional TKA operated at four U.S. centers between July 2016 and October 2018. Computed tomography (CT) scans obtained approximately 6 weeks postoperatively were analyzed using anatomical landmarks. Absolute deviation from surgical plans were defined as the absolute value of the difference between the CT measurements and surgeons' femoral and tibial component mechanical varus/valgus alignment, tibial component posterior slope, and femoral component internal/external rotation. Differences of absolute deviations were tested using stratified Wilcoxon's tests that controlled for study center. Patient-reported outcome measures collected through 1 postoperative year were modeled using multiple regression controlling for age, sex, body mass index, study center, and the preoperative score. RATKA demonstrated greater accuracy for tibial component alignment (median [25th, 75th percentiles] absolute deviation from plan of all centers combined for conventional vs. RA, $1.7[0.9,2.9]$ vs. $0.9[0.4,1.9]$ degrees, $p<0.001)$, femoral component rotation $(1.5[0.9,2.5]$ vs. $1.3[0.6,2.5]$ degrees, $p=0.015)$, and tibial slope $(2.9[1.5,5.0]$ vs. $1.1[0.6,2.0]$ degrees, $p<0.001)$. In multivariable analyses, RATKA showed significantly greater Veterans RAND 12-item health survey (VR-12) physical component scores (adjusted mean difference [95\% confidence interval $(\mathrm{Cl})]: 2.4[0.2,4.5]$ points, $p=0.034)$ and qualitatively greater Knee Society (KS) composite functional scores $(3.5[-1.3,8.2]$ points, $p=0.159)$, though not statistically significant. Compared with conventional instrumentation, RATKA demonstrated greater three-dimensional accuracy to plan for various component positioning parameters and clinical improvements in physical status and function with no major safety concerns during the first postoperative year. These results may be attributed to the received

March 7, 2020

accepted

June 25, 2020

published online

August 31, 2020 (c) 2020. Thieme. All rights reserved.

Thieme Medical Publishers, Inc., 333 Seventh Avenue, 18th Floor, New York, NY 10001, USA
DOI https://doi.org/

10.1055/s-0040-1715571. ISSN 1538-8506. 
preoperative CT scan planning, real-time intraoperative feedback, and stereotacticguided cutting that takes into consideration patient-specific bony anatomy. These findings support the use of RATKA for enhanced arthroplasty outcomes.

Total knee arthroplasties are traditionally performed by orthopaedic surgeons using tools and mechanical instruments including hand-held power tools, intramedullary canal rods, extramedullary jigs, and mechanical blocks. Such mechanicaland visual-based techniques have been the time-tested standard of care for decades; however, some variation in accuracy of these techniques and technical results of surgeries are inherent. ${ }^{1,2}$ These variations may be important because certain prosthetic placement deviations have been recognized as risk factors for prosthetic loosening, a complication that necessitates an extensive reoperation. ${ }^{3-9}$

Several modern technologies have been developed to assist with improvement of cut accuracy including computerassisted infrared tracking guidance systems or "navigated" total knee arthroplasty (TKA) ${ }^{10}$ and patient-specific instrumentation or cutting guides. However, studies have failed to demonstrate improved short- or long-term clinical outcomes with the use of these technologies, ${ }^{10-12}$ despite high-cost differentials. As a result, these technologies have been only selectively adopted by the orthopaedic community.

The mechanical and computer-assistive tools described above are designed to provide informational and physical guidance to the surgeon in the performance of all the resections (cuts) for the operation. In contrast, a roboticarm assisted (RA) system places virtual boundaries on the surgeon's movements based on the computer's prior threedimensional "knowledge" of the particular patient's anatomy. ${ }^{13}$ The Stryker robotic arm system (Mako; MAKO Surgical Corp., Ft. Lauderdale, FL) uses optical motion capture technology to track markers attached to the bones; this method of tracking enables the guidance system to constantly orient itself so that the surgeon may freely adjust the position of the leg anytime during the procedure. ${ }^{14,15}$ A preoperative computerized tomography (CT) scan of the leg provides the data inputs that allow for preoperative planning, intraoperative navigation, and the creation of a stereotactic interface that disallows the surgeon to move the cutting tip beyond predefined boundaries for the operation. ${ }^{16}$ The system tools essentially function as virtual cutting guides and templates that replace the physical guides and templates used with conventional instrument systems. ${ }^{13,15}$ Studies of RA technology for unicompartmental knee arthroplasty (UKA) have demonstrated surgical accuracy with high reproducibility and improved prosthesis position/placement compared with traditional instrumentation systems. ${ }^{14-16}$

However, there have been fewer studies for RATKA than for UKA. In one cadaver study, the authors compared component position and accuracy in six conventional versus RATKA, and found RATKA to be as or more accurate to plan based on nominal median values in 11 out of 12 measurements, and more precise to plan in 8 out of 12 measurements $(p \leq 0.05) .{ }^{17}$ In two other cadaver studies, less iatrogenic soft tissue damage was found using RATKA. ${ }^{18,19}$ Recently, there have been a few short-term studies describing clinical results of RATKA. ${ }^{20-25}$

Studies of the ability of RATKA to precisely execute a preoperative bone-cut plan have so far been limited mostly to cadaveric models. The continued evaluation of this surgical tool, especially in a clinical setting, is consequently critical to further highlight the device's use in the operating room. Thus, the primary objective of this study was to compare the three-dimensional prosthesis placement accuracy to plan and short-term clinical outcomes of patients who underwent TKA implanted with the use of an RA system compared with manual instrumentation. Specifically, we aimed to (1) compare accuracy of femoral and tibial component placement following TKA implanted using an RA system with that of TKA implanted using the investigators' standard technique based on conventional instrument systems, and (2) describe short-term ( $\leq 1$ year) patient-reported functional recovery and satisfaction scores of patients undergoing both procedures.

\section{Methods}

We undertook a prospective open-label nonrandomized study to compare an RATKA system (Stryker robotic arm system [Mako], MAKO Surgical Corp., Fort Lauderdale, FL) with conventional instrumentation in primary TKA at four clinical sites (Athens Orthopedic Clinic, Athens, GA; Rothman Institute, Philadelphia, PA; Rothman Institute, Egg Harbor Township, NJ; and Cleveland Clinic, Cleveland, OH). Patients over 18 years who were scheduled for a primary TKA were recruited for the study. Eligible patients at each center were enrolled into RATKA or conventional instrumentation cohorts according to the same eligibility criteria (-Table $\mathbf{1}$ ).

This report includes 229 TKA (86 conventional and 143 RA) of 223 patients operated on between July 27, 2016 and October 12,2018 , who had fully analyzable postoperative computed tomography (CT) scans and completely recorded component placement target data. Follow-up evaluations were obtained at approximately 4 to 6 weeks, 3 months, 6 months, and 12 months postoperatively for $220,202,208$, and 195 cases, respectively. The preoperative characteristics of the patients are shown in - Tables $\mathbf{2}$ and $\mathbf{3}$.

Patients in the RATKA cohort were significantly younger (mean difference 4 years, $p<0.001$ ) and of larger proportion female (69 vs. 55\%, $p=0.024$ ) than the conventional TKA cohort (-Table 2 ). The preoperative body mass index (BMI), limb deformity, and patient-reported outcome measure (PROM) scores (described later) of the two cohorts were comparable (-Tables $\mathbf{2}$ and $\mathbf{3}$ ). 
Table 1 Patient eligibility criteria

\begin{tabular}{|l|}
\hline Inclusion criteria \\
\hline Use of triathlon CR total knee system is indicated \\
\hline Body mass index $\leq 40 \mathrm{~kg} / \mathrm{m}^{2}$ \\
\hline $\begin{array}{l}\text { Willing and able to undergo postoperative follow-up } \\
\text { requirements and self-evaluations }\end{array}$ \\
\hline $\begin{array}{l}\text { Gives valid informed consent and signs the required } \\
\text { informed consent and privacy authorization forms }\end{array}$ \\
\hline Exclusion criteria \\
\hline Body mass index $>40 \mathrm{~kg} / \mathrm{m}^{2}$ \\
\hline $\begin{array}{l}\text { Prior high tibial osteotomy or previous reconstruction to } \\
\text { the affected knee including partial arthroplasty }\end{array}$ \\
\hline $\begin{array}{l}\text { Neuromuscular disorders, muscular atrophy, or vascular } \\
\text { deficiency in the affected limb }\end{array}$ \\
\hline Skeletally immaturity \\
\hline Active or suspected infection in or about the joint \\
\hline $\begin{array}{l}\text { Bone stock that is inadequate to support fixation of the } \\
\text { prosthesis }\end{array}$ \\
\hline Collateral ligament insufficiency \\
\hline $\begin{array}{l}\text { Blood supply limitations, refusal to receive blood trans- } \\
\text { fusions, or medical condition that predisposes patient to } \\
\text { increased risk of blood loss }\end{array}$ \\
\hline $\begin{array}{l}\text { Mental or neurological conditions that may interfere with } \\
\text { ability to provide self-reported data }\end{array}$ \\
\hline Patient is nonambulatory, medically frail, or critically ill \\
\hline Female patient is pregnant or lactating \\
\hline Patient is incarcerated \\
\hline Patient cannot or does not give valid informed consent \\
\hline
\end{tabular}

Abbreviation: $C R$, cruciate retaining.

Eight high-volume arthroplasty fellowship-trained surgeons performed the surgeries using the same cruciate retaining device with fully cemented implantation (Triathlon Cruciate Retaining Total Knee System, Stryker Orthopaedics, Mahwah, NJ). The surgeons targeted a neutral mechanical axis (0 degrees) for all except nine cases of two centers that were targeted within \pm 3 degrees. The routines of peri- and postoperative care were the same for conventional and RATKA cohorts at each center. Rehabilitation protocols were similar across the centers, with weight bearing as tolerated beginning at 1 day after surgery and progressing to full weight bearing with light strength training as tolerated.

\section{Data Collection}

For both the conventional and RATKA cohorts, the surgeon's final intraoperative target for femoral and tibial component varus/valgus position from the mechanical axes, femoral component internal/external rotation from the transepicondylar axis, and tibial component posterior slope were recorded intraoperatively. A CT scan of the lower extremity (hip, knee, and ankle joints) was then obtained at approximately 6 weeks postoperatively and analyzed using anatomic landmarks to determine the three-dimensional final placement of the femoral and tibial components. ${ }^{26,27}$ Accuracy of component place-
Table 2 Baseline patient characteristics

\begin{tabular}{|c|c|c|c|c|}
\hline & Center $^{a}$ & $\begin{array}{l}\text { Conventional } \\
(n=86)\end{array}$ & $\begin{array}{l}\text { RATKA } \\
(n=143)\end{array}$ & $p$-Value ${ }^{b}$ \\
\hline \multirow{5}{*}{$\begin{array}{l}\text { Age }(y) \\
\text { Mean (SD) }\end{array}$} & All & $68.5(8.4)$ & $64.6(8.3)$ & \multirow[t]{5}{*}{0.001} \\
\hline & 1 & $69.4(7.0)$ & 66.8 (6.7) & \\
\hline & 2 & $66.1(8.3)$ & 63.9 (8.6) & \\
\hline & 3 & $69.4(7.8)$ & $64.8(7.9)$ & \\
\hline & 4 & $68.9(10.1)$ & $62.6(10.1)$ & \\
\hline \multirow{5}{*}{$\begin{array}{l}\text { BMI }\left(\mathrm{kg} / \mathrm{m}^{2}\right) \\
\text { Mean }(\mathrm{SD})\end{array}$} & All & $30.6(4.0)$ & $30.7(4.6)$ & \multirow[t]{5}{*}{0.621} \\
\hline & 1 & $29.5(3.6)$ & $31.0(4.4)$ & \\
\hline & 2 & $30.8(4.1)$ & $30.6(4.4)$ & \\
\hline & 3 & $31.2(4.2)$ & $30.2(4.9)$ & \\
\hline & 4 & $31.3(4.9)$ & $31.7(4.9)$ & \\
\hline \multirow{5}{*}{$\begin{array}{l}\text { Sex } \\
n(\%) \text { female }\end{array}$} & All & $47(55)$ & $98(69)$ & \multirow[t]{5}{*}{0.024} \\
\hline & 1 & $14(47)$ & $16(53)$ & \\
\hline & 2 & $14(70)$ & $31(78)$ & \\
\hline & 3 & $8(57)$ & $36(78)$ & \\
\hline & 4 & $11(50)$ & $15(56)$ & \\
\hline \multicolumn{5}{|c|}{ Preoperative deformity $n(\%)^{c}$} \\
\hline$>10$ valgus & \multirow[t]{6}{*}{ All } & $6(7)$ & $4(3)$ & \multirow[t]{6}{*}{0.158} \\
\hline$>5-10$ valgus & & $9(11)$ & $12(9)$ & \\
\hline$>0-5$ valgus & & $8(10)$ & $14(10)$ & \\
\hline $0-5$ varus & & $9(11)$ & $35(25)$ & \\
\hline$>5-10$ varus & & $33(40)$ & $46(33)$ & \\
\hline$>10$ varus & & $17(21)$ & $29(21)$ & \\
\hline
\end{tabular}

Abbreviations: BMI, body mass index; RATKA, robotic-arm assisted total knee arthroplasty; SD, standard deviation.

a'Sample sizes per site (conventional/RATKA) were (1) 30/30, (2) 20/40, (3) $14 / 46$, and (4) $22 / 27$.

bLinear regression controlling for study center for age and BMI. Cochran-Mantel-Haenszel tests controlling for study center for sex and preoperative deformity category.

'Hip-knee-ankle angle measured from weight bearing long radiographs, available for 82 conventional and 140 RATKA (radiograph was missing for 1 ; view was insufficient for 6 ).

ment was represented as a lack of a difference between the intended position in a given plane (determined during preoperative planning and/or confirmed intraoperatively), and the resultant placement determined from the postoperative CT scan. As such, a nonzero difference quantified a deviation from accuracy.

PROMs (2011 Knee Society [KS] scoring system ${ }^{28,29}$ and Veterans RAND 12-item health survey [VR-12] $)^{30,31}$ were administered preoperatively and at 4 to 6 weeks and 3, 6, and 12 months postoperatively. The KS scoring system includes validated self-administered instruments for evaluating satisfaction (five questions), expectations (three questions), and function (composite of four subscales) specific to patients who undergo knee arthroplasty, and the scores range from 0 to 40,0 to 15 , and 0 to 100 points, respectively, with higher scores corresponding to better outcomes. The KS scoring system also includes a 0 - to 25-point symptom assessment (three questions relating primarily to pain with higher scores corresponding to better outcomes), which was designed to 
Table 3 Preoperative patient-reported outcome measures

\begin{tabular}{|l|l|l|l|l|}
\hline & $\begin{array}{l}\text { Score } \\
\text { range }^{\mathrm{a}}\end{array}$ & Conventional $^{\mathrm{b}}$ & RATKA & -Value $^{\mathrm{s}}$ \\
\hline $\begin{array}{l}\text { 2011 Knee Society scoring system } \\
\text { Mean (SD) }\end{array}$ & \multicolumn{5}{|l|}{} \\
\hline Symptoms & $0-25$ & $8.6(4.6)$ & $8.0(4.6)$ & 0.311 \\
\hline Satisfaction & $0-40$ & $13.8(6.0)$ & $12.7(7.2)$ & 0.121 \\
\hline Expectations & $0-15$ & $13.9(1.7)$ & $14.2(1.6)$ & 0.267 \\
\hline Function & $0-100$ & $40.8(15.3)$ & $39.7(16.2)$ & 0.636 \\
\hline $\begin{array}{l}\text { Veterans RAND } \\
\text { Mean (SD) }\end{array}$ & 12 -item health scale & \\
\hline $\begin{array}{l}\text { Physical } \\
\text { component }\end{array}$ & $0-100$ & $36.7(9.6)$ & $39.5(10.3)$ & 0.931 \\
\hline $\begin{array}{l}\text { Mental } \\
\text { component }\end{array}$ & $0-100$ & $51.0(10.6)$ & $52.4(10.6)$ & 0.645 \\
\hline
\end{tabular}

Abbreviations: RATKA, robotic-arm assisted total knee arthroplasty; SD, standard deviation.

${ }^{\mathrm{a} A}$ higher score corresponds to better patient status for all scores.

bSample sizes per center for conventional/RATKA were (1) 30/30, (2) $20 / 40$, (3) $14 / 46$, and (4) 22/27. Preoperative patient-reported outcome measures were missing for one patient of center 3 . Scores shown are for all sites combined.

${ }^{\mathrm{C}}$ Tested using linear regression controlling for study center.

be scored by the physician examiner. The VR-12 is a validated 12-item questionnaire for assessment of general health and health-related quality of life. This instrument provides mental and physical component norm-based scores (100 points each, higher scores corresponding to better outcomes) that are calibrated to a population mean of 50 and a standard deviation (SD) of 10 . One center administered the Short Form-12 (SF-12) $)^{32}$ as per their institutional routine, those SF-12 scores were then translated to VR-12 equivalent scores using established methods. ${ }^{30,33}$ Serious adverse events were recorded at each follow-up evaluation. Three sites used research electronic data capture ${ }^{34}$ for collation of data and one site used a local database.

\section{Statistical Methods}

For component placement accuracy, differences of mean CTderived postoperative component positions were tested using linear regression analyses that controlled for study center. Absolute deviations from surgical plan were calculated as the absolute values of the differences of the position measured by CT scans and the surgeon's operative plans. Differences of the absolute deviations between conventional and RA cohorts were tested using stratified Wilcoxon's tests (i.e., Van Elteren's test) that controlled for study center and accounted for the skewed distributions of the absolute values.

Differences between the conventional and RATKA cohorts of ages, BMIs, and preoperative PROM scores were tested using separate linear regression models that controlled for study center. Terms for interaction of surgery type with study center were nonsignificant $(>0.05)$ for all preoperative variables were, therefore, removed from the models. ${ }^{35}$ Categorical variables (sex, preoperative alignment deformity, and adverse event count) were tested using Cochran-MantelHaenszel tests that controlled for study center.
Overall mean PROM scores and postoperative recovery trends were characterized graphically. Multivariable linear regression models that controlled for age, sex, BMI, study center, and the patient's preoperative score were used to estimate adjusted mean scores with 95\% confidence intervals (CIs) of conventional and RA cohorts and the adjusted mean difference between the groups of PROM scores 1 year after surgery. Terms for interaction of surgery type with study center and sex with the preoperative PROM score ${ }^{36}$ were nonsignificant $(p>0.05)$ for all outcomes and were therefore removed from the models.

SAS 9.4 software (SAS Institute, Cary, NC) was used for all analyses. Alpha was set at 0.05 for statistical tests.

Prestudy sample size planning was based on a onesample test for statistical significance of positional accuracy deviation. The power analysis showed that 24 patients per treatment group would provide a $>80 \%$ power at $\alpha=0.05$ to detect an effect size of 1.5 assuming a normal distribution with $\sigma^{2}$ of 1.5 degrees, corresponding to a detectable delta of 0.73 degree for coronal plane positional accuracy deviation.

\section{Registration}

This study is registered at ClinicalTrials.gov (NCT03106558 and NCT02830997).

\section{Results}

Coronal positions of the femoral components measured via CT for conventional and RATKA cohorts, respectively, were (mean \pm SD of all sites combined) $0.1 \pm 1.6$ varus and $0.0 \pm 1.4$ varus $(p=0.506)$; positions of the tibial components were $1.9 \pm 2.4$ varus and $0.9 \pm 2.0$ varus $(p=0.005)$. Positions of external femoral component rotation relative to the transepicondylar axis were $1.1 \pm 2.3$ and $0.5 \pm 2.3$ degrees, respectively $(p=0.195)$. Tibial slopes were $3.7 \pm 3.0$ and $3.2 \pm 1.8$ degrees, respectively $(p=0.291)$.

Comparing absolute deviation from the surgeon's plan between the groups, RATKA demonstrated greater accuracy for tibial component alignment (median [25th, 75th percentiles] absolute deviation from plan of all centers combined for conventional vs. RA, $1.7[0.9,2.9]$ vs. $0.9[0.4,1.9]$ degrees, $p<.001)$, femoral component rotation $(1.5[0.9,2.5]$ vs. 1.3 $[0.6,2.5]$ degrees, $p=0.015)$, and tibial slope $(2.9[1.5,5.0]$ vs. $1.1[0.6,2.0]$ degrees, $p<0.001$; - Table 4). Femoral component alignment was comparable $(1.0[0.4,1.7]$ vs. 0.9 [0.4, 1.5] degrees, $p=0.159$; - Table 4).

For all PROMs, longitudinal trends of postoperative recovery for conventional and RATKA cohorts were qualitatively similar (-Figs. 1A-F). In multivariable analyses of PROM scores at final follow-up (1-year postoperative) that controlled for age, sex, BMI, study center, and the patient's preoperative PROM score, RATKA showed significantly greater VR-12 physical component score (mean difference [95\% $\mathrm{CI}]: 2.4[0.2,4.5]$ points, $p=0.034$ ) and qualitatively greater KS composite functional score $(3.5[-1.3,8.2]$ points, $p=0.159$ ) though not statistically significant ( - Table 5 ).

Serious adverse events included one deep vein thrombosis (RATKA) and four medical rehospitalizations (three 
Table 4 Absolute deviation from surgical plan ${ }^{a}$ by study center

\begin{tabular}{|c|c|c|c|c|}
\hline & Center $^{\mathrm{b}}$ & Conventional $(n=86)$ & RATKA $(n=144)$ & \multirow[t]{2}{*}{$p$-Value ${ }^{c}$} \\
\hline & & \multicolumn{2}{|c|}{ Degree (mean/median [25th, 75th percentiles]) } & \\
\hline \multirow{5}{*}{$\begin{array}{l}\text { Femoral } \\
\text { component } \\
\text { alignment }\end{array}$} & All & $1.2 / 1.0[0.4,1.7]$ & $1.0 / 0.9[0.4,1.5]$ & \multirow[t]{5}{*}{0.137} \\
\hline & 1 & $0.9 / 0.9[0.3,1.3]$ & $0.8 / 0.8[0.3,1.1]$ & \\
\hline & 2 & $1.0 / 0.9[0.5,1.5]$ & $0.9 / 0.9[0.3,1.3]$ & \\
\hline & 3 & $1.4 / 1.4[0.6,1.7]$ & $1.2 / 0.9[0.6,1.8]$ & \\
\hline & 4 & $1.8 / 1.5[0.3,2.7]$ & $1.0 / 0.7[0.4,1.7]$ & \\
\hline \multirow{5}{*}{$\begin{array}{l}\text { Femoral } \\
\text { component } \\
\text { rotationd }^{d}\end{array}$} & All & $1.9 / 1.5[0.9,2.5]$ & $1.7 / 1.3[0.6,2.5]$ & \multirow[t]{5}{*}{0.015} \\
\hline & 1 & $1.9 / 1.4[0.9,2.5]$ & $1.1 / 0.9[0.7,1.5]$ & \\
\hline & 2 & $1.9 / 1.9[1.1,2.5]$ & $1.8 / 1.5[0.8,2.6]$ & \\
\hline & 3 & $1.9 / 1.5[0.8,2.8]$ & $1.7 / 1.5[0.5,2.6]$ & \\
\hline & 4 & $1.8 / 1.5[0.9,2.5]$ & $2.1 / 2.0[0.6,3.5]$ & \\
\hline \multirow{5}{*}{$\begin{array}{l}\text { Tibial } \\
\text { component } \\
\text { alignment }\end{array}$} & All & $2.3 / 1.7[0.9,2.9]$ & $1.3 / 0.9[0.4,1.9]$ & \multirow[t]{5}{*}{$<0.001$} \\
\hline & 1 & $1.4 / 1.2[0.8,1.8]$ & $1.0 / 0.7[0.4,1.2]$ & \\
\hline & 2 & $3.1 / 2.7[1.4,4.4]$ & $1.4 / 1.1[0.6,2.4]$ & \\
\hline & 3 & $2.1 / 1.7[0.9,2.9]$ & $1.4 / 1.0[0.4,2.3]$ & \\
\hline & 4 & $3.0 / 2.4[1.2,4.2]$ & $1.5 / 0.9[0.4,1.9]$ & \\
\hline \multirow{5}{*}{$\begin{array}{l}\text { Tibial } \\
\text { component } \\
\text { slope }\end{array}$} & All & $3.2 / 2.8[1.5,4.6]$ & $1.4 / 1.1[0.6,2.0]$ & \multirow[t]{5}{*}{$<0.001$} \\
\hline & 1 & $3.1 / 2.5[0.8,4.8]$ & $1.2 / 1.0[0.5,1.5]$ & \\
\hline & 2 & $4.6 / 4.6[3.6,6.3]$ & $2.0 / 2.0[0.9,2.7]$ & \\
\hline & 3 & $2.0 / 1.9[1.3,2.8]$ & $1.1 / 0.9[0.6,1.7]$ & \\
\hline & 4 & $2.9 / 2.8[1.4,4.3]$ & $1.5 / 1.4[0.7,1.7]$ & \\
\hline
\end{tabular}

Abbreviation: RATKA, robotic-arm assisted total knee arthroplasty.

${ }^{a}$ Calculated as the absolute value of (computed tomography position minus surgeon's target position).

bSample sizes per center for conventional/RATKA were (1) 30/30, (2) 20/40, (3) 14/46, and (4) 22/27.

'Stratified Wilcoxon's (Van Elteren's) test controlling for study center.

${ }^{\mathrm{d}}$ Referenced from the transepicondylar axis.

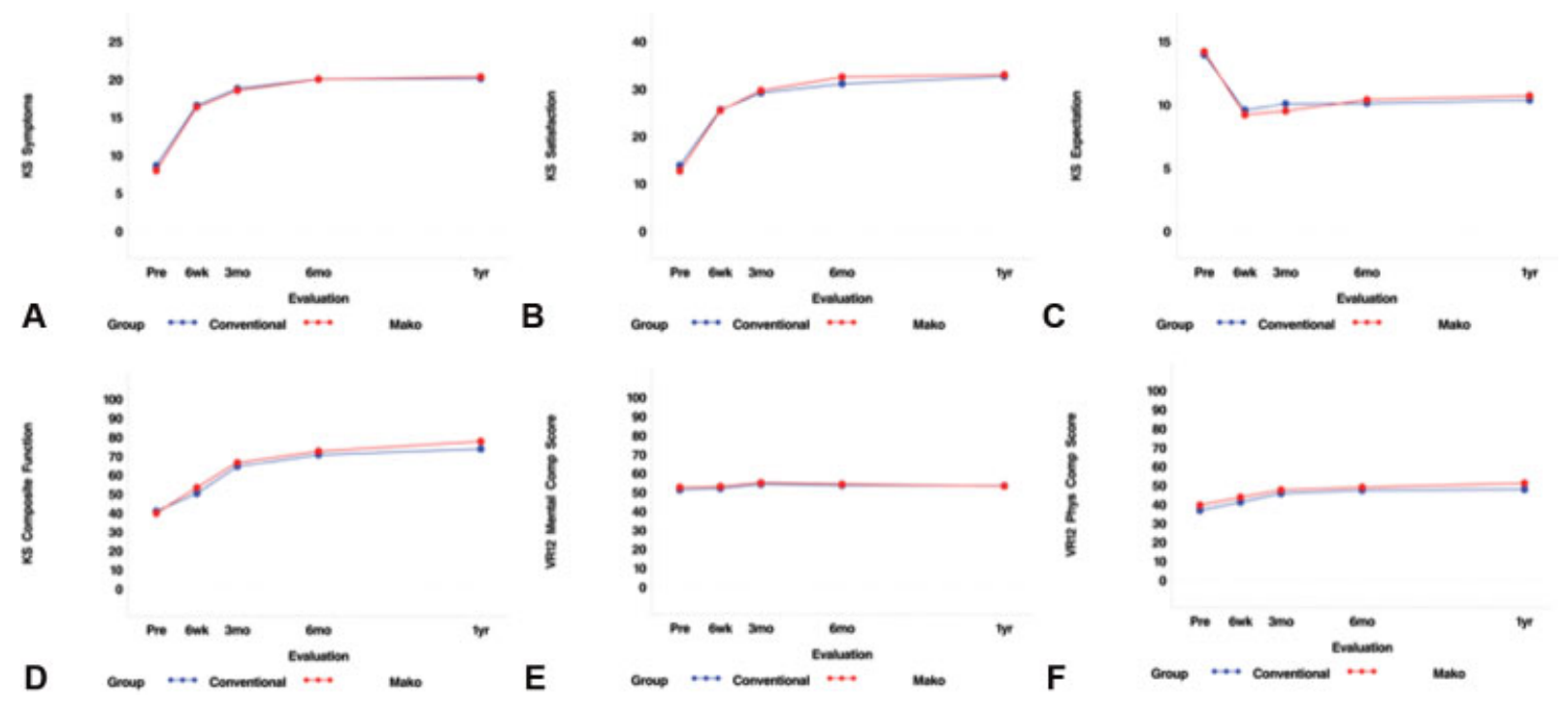

Fig. 1 (A-F) Mean patient reported outcome measure scores over 1 postoperative year follow-up for all sites combined are shown: The 2011 Knee Society (KS) scoring system symptoms (A), satisfaction (B), expectations (C), and composite functional (D) scores, mental component (E), and the Veterans RAND 12-item Health Survey (VR-12) physical component (F) scores. For all outcome measures, a higher score corresponds to a better patient outcome. 
Table 5 Multivariable adjusted ${ }^{\mathrm{a}}$ 1-year postoperative PROM scores

\begin{tabular}{|c|c|c|c|c|c|}
\hline & Score range $^{\mathrm{b}}$ & Conventional $^{c}$ & RATKA $^{c}$ & Difference & $p$-Value \\
\hline \multicolumn{6}{|c|}{2011 Knee Society scoring system (adjusted mean [95\% confidence interval]) } \\
\hline Symptoms & $0-25$ & $20.3[18.4,22.2]$ & $20.8[18.9,22.7]$ & $0.5[-1.0,1.9]$ & 0.531 \\
\hline Satisfaction & $0-40$ & $35.2[32.0,38.4]$ & $35.9[32.6,39.2]$ & $0.7[-1.5,3.0]$ & 0.532 \\
\hline Expectations & $0-15$ & $10.6[9.2,12.0]$ & $11.2[9.7,12.7]$ & $0.7[-0.3,1.6]$ & 0.192 \\
\hline Function & $0-100$ & $81.1[75.5,86.8]$ & $84.6[78.8,90.4]$ & $3.5[-1.3,8.2]$ & 0.159 \\
\hline \multicolumn{6}{|c|}{ Veterans RAND 12-item health scale (adjusted mean [95\% confidence interval]) } \\
\hline Physical & $0-100$ & $50.5[47.5,53.5]$ & $52.9[49.9,55.9]$ & $2.4[0.2,4.5]$ & 0.034 \\
\hline Mental & $0-100$ & $56.0[53.7,58.3]$ & $54.6[52.2,57.0]$ & $-1.3[-3.5,0.7]$ & 0.213 \\
\hline
\end{tabular}

Abbreviations: PROM, patient-reported outcome measure; RATKA, robotic-arm assisted total knee arthroplasty.

${ }^{a}$ Estimated from multivariable linear regression models adjusting for age, sex, body mass index (BMI), study center, preoperative score, and interaction of sex with preoperative score. Continuous covariates were centered on their mean values, therefore the estimated mean scores shown for conventional and RATKA represent the expected values for a female from center 1 aged 66 years with BMI $=30.6 \mathrm{~kg} / \mathrm{m}^{2}$ and preoperative score equal to the mean of the study population (an "average" patient). Estimated differences shown represent the expected mean score differences between groups adjusted for all covariates. Model $R^{2}$ were $0.040,0.033,0.038,0.121,0.234$, and 0.506 respective to the order listed.

${ }^{b}$ Higher score corresponds to better patient outcome for all scores.

'Total cases per center for conventional/RATKA that underwent 1-year follow-up were (1) 28/28, (2) 20/35, (3) 11/34, and (4) 17/22; for all sites combined, they were 76/119. Of those, individual 1-year PROM scores were missing or incomplete for 9, 2, 3, 2, 3, and 3 cases, respective to the order of PROMs listed above.

conventional and one RATKA) within the immediate postoperative period $(<15$ days) due to shortness of breath, hyponatremia, bradycardia, and cellulitis. Two patients (one conventional and one RATKA) underwent wound reclosure following traumatic dehiscence. Nine conventional (9\%) and 11 RATKA (8\%) underwent closed manipulation under anesthesia for decreased range of motion and/or stiffness $(p=0.830)$. There were no deep wound infections, loosenings, removals, or revisions of components, or deaths during the follow-up period.

\section{Discussion}

Accurate and precise implant positioning is critical to achieve optimal, patient-specific component placement. We found that certain radiographic component positioning parameters were improved for the RATKA cohort when compared with conventional instrumentation, specifically the accuracy of tibial component alignment, femoral component rotation, and tibial slope. The increased accuracy and precision may be attributed to the real-time, intraoperative feedback that takes into consideration a patient's specific bony anatomy, helping guide patient-specific bone cuts. The increased surgical accuracy seen with RATKA was accompanied by clinical improvements of postoperative physical status and function ( - Table 5 ) with no major safety concerns during the first postoperative year.

\section{Limitations and Strengths}

The principal limitations of our study were the nonrandomized design and lack of follow-up beyond 1 postoperative year. We controlled for baseline imbalances in the analyses of PROMs using multivariable models, and we accounted for center-to-center variation in all analyses. Nevertheless, this study represents a prospective, multicenter trial and is one of the first of its kind to directly compare RATKA and conventional position outcomes in a clinical setting. These findings provide the baseline for future work with long-term follow-up.

In addition to the component position advantages found in this study, other studies have also identified several advantages with this system. Regarding preoperative planning, one study evaluating 335 RATKA patients found accurate prediction of tibial and femoral implant sizes $98 \%$ of the time. ${ }^{22}$ Other studies have found RATKA patients to have superior clinical patient satisfactions $(p<0.05)$, and lower postoperative pain $(p<0.05)$ at 6 -month follow-up, ${ }^{23}$ as well as higher total and physical function scores at 1-year $(p<0.05) .{ }^{37}$ At 2 years, RATKA patients were also found to have excellent outcomes as assessed by multiple patientreported outcome metrics, including the SF-12 Questionnaire, the Forgotten Joint Score (FJS), and Knee Society total and subscores (KSS). ${ }^{24}$ Additionally, one multicenter study of 188 consecutive RATKA versus conventional controls found RATKA patients to have a significantly lower manipulation under anesthesia rate ( 1.06 vs. $4.79 \% ; p=0.032$ ), though the results from this study found no difference. ${ }^{25}$

Furthermore, some studies have found the haptic-feedback of the RA saw to provide soft-tissue protection by creating bony islands around the posterior-cruciate ligament. ${ }^{18,19,38,39}$ In a cadaver study, 12 fresh-frozen specimens that underwent RATKA versus conventional instrumentation TKA were evaluated based on key anatomical structures. With RATKA, the authors found substantially less damage to the posterior cruciate ligament $(p<0.001)$, deep medial collateral ligaments $(p=0.149)$, iliotibial bands $(p=0.580)$, poplitei $(p=0.248)$, and patellar ligaments $(p=0.317) .{ }^{18}$ The sparing of these major structures is concurrent with the more optimal component positioning and placement. Similar to the present study, Nickel et al assessed 105 RATKA patients and found this system to be 
highly reliable and accurate in terms of tibial coronal, femoral coronal, and tibial sagittal component alignment at 1 year postoperative compared with intraoperative alignment. ${ }^{40}$

Other devices have also been developed to assist in optimizing TKA. In a study of a robotic TKA system, the authors assessed the accuracy of targeted angles and the resection thickness of bone cuts using 30 cadaveric knees and found bone cuts to be made with a high degree of accuracy. ${ }^{41}$ In another study, Jaramaz et al ${ }^{42}$ compared final versus planned femoral and tibial component placement and found root mean squares for both component placements to be $<1$ degree for varus/valgus, rotation, and posterior slope, as well as $<1 \mathrm{~mm}$ for distal resection.

\section{Conclusion}

In this study, we compared the accuracy to plan of RATKA with conventional TKA in a cohort of 229 patients from four clinical centers. We found that certain three-dimensional component positioning parameters were improved for the RATKA cohort when compared with conventional instrumentation. We also saw subclinical improvements of patient-reported physical status and function scores with no major safety concerns 1 year after surgery. These results may be attributed to the preoperative CT scan planning, the real-time, intraoperative feedback, and the stereotactic-guided cutting that takes into consideration a patient's specific bony anatomy. Although further confirmatory clinical studies with longer follow-up are necessary, these findings further support the use of this device for enhanced total knee arthroplasty outcomes.

\section{Ethical Approval}

The institutional review boards at each center approved this study. Written informed consent was obtained from all participants. All devices and instruments used in this study were cleared by the Food and Drug Administration.

\section{Funding}

This study was funded by Stryker Orthopaedics.

\section{Conflict of Interest}

T.K. reports other from Stryker, other from Arthrex, Inc., during the conduct of the study; other from Surgical Devices, Inc., from Journal of Arthroplasty, outside the submitted work. A.F.C. reports other from Stryker, during the conduct of the study; other from $3 \mathrm{M}$, other from AAOS, other from ACI, other from AJRR, other from AAHKS, from American Medical Foundation, other from Annals of Joint, other from Avanos, other from bOne, other from Bone \& Joint 360 Journal, other from Clinical Orthopaedics and Related Research, other from Convatec, other from DePuy, other from European Knee Society, other from Graftworx, other from Healthcare Transformation, other from Hereaus, other from Hyalex, other from International Congress for Joint Reconstruction, other from Irrimax, other from Joint Purification Systems, other from Journal of Arthroplasty, other from Journal of Bone \& Joint Infection, other from Journal of Bone and Joint Surgery-
American, other from Knee Surgery, Sports Traumatology, Arthroscopy, other from Musculoskeletal Infection Society, other from PhagoMed, other from Recro, other from SLACK Incorporated, other from Sonoran, and other from UpToDate outside the submitted work. O.M. reports other from Stryker, during the conduct of the study; other from Surgical Devices, Inc., outside the submitted work. F.O. reports other from Stryker, during the conduct of the study. W.H. reports other from Stryker, during the conduct of the study; other from Journal of Arthroplasty, outside the submitted work. All the other authors report no conflict of interest.

\section{Acknowledgments}

The authors gratefully acknowledge the assistance of Tiffany Morrison, MS, and Reynaldo McFarlane, MHA, of the Rothman Orthopaedic Institute, Alison Klika, MS, and Anabelle Visperas, PhD, of the Department of Orthopaedic Surgery, Cleveland Clinic, and Laurel Kuhr, CCRP, of the Athens Orthopedic Clinic with patient recruitment and data collection; Paul Territo, PhD, Scott Persohn, BA, and Meenakshisundaram Paramasivam, MS, of the Department of Radiology and Imaging Sciences, Indiana University School of Medicine with technical analyses of CT scans; Mohammad Abdelaal, MD, of the Rothman Orthopaedic Institute with radiographic analyses; and Manoshi Bhowmik-Stoker, PhD, and Jingwei Zhang, PhD, of Stryker Orthopaedics Implant and Robotics Research with technical support.

\section{References}

1 Choong PF, Dowsey MM, Stoney JD. Does accurate anatomical alignment result in better function and quality of life? Comparing conventional and computer-assisted total knee arthroplasty. J Arthroplasty 2009;24(04):560-569

2 Berend ME, Ritter MA, Meding JB, et al. Tibial component failure mechanisms in total knee arthroplasty. Clin Orthop Relat Res 2004;(428):26-34

3 Hvid I, Nielsen S. Total condylar knee arthroplasty. Prosthetic component positioning and radiolucent lines. Acta Orthop Scand 1984;55(02):160-165

4 Jeffery RS, Morris RW, Denham RA. Coronal alignment after total knee replacement. J Bone Joint Surg Br 1991;73(05):709-714

5 Lotke PA, Ecker ML. Influence of positioning of prosthesis in total knee replacement. J Bone Joint Surg Am 1977;59(01):77-79

6 Moreland JR. Mechanisms of failure in total knee arthroplasty. Clin Orthop Relat Res 1988;(226):49-64

7 Ritter MA, Davis KE, Meding JB, Pierson JL, Berend ME, Malinzak RA. The effect of alignment and BMI on failure of total knee replacement. J Bone Joint Surg Am 2011;93(17):1588-1596

8 Ritter MA, Faris PM, Keating EM, Meding JB. Postoperative alignment of total knee replacement. Its effect on survival. Clin Orthop Relat Res 1994;(299):153-156

9 Ethgen $O$, Bruyère $O$, Richy F, Dardennes $C$, Reginster JY. Healthrelated quality of life in total hip and total knee arthroplasty. A qualitative and systematic review of the literature. J Bone Joint Surg Am 2004;86(05):963-974

10 Abane L, Anract P, Boisgard S, Descamps S, Courpied JP, Hamadouche M. A comparison of patient-specific and conventional instrumentation for total knee arthroplasty: a multicentre randomised controlled trial. Bone Joint J 2015;97-B (01):56-63 
11 Sassoon A, Nam D, Nunley R, Barrack R. Systematic review of patient-specific instrumentation in total knee arthroplasty: new but not improved. Clin Orthop Relat Res 2015;473(01):151-158

12 Burnett RS, Barrack RL. Computer-assisted total knee arthroplasty is currently of no proven clinical benefit: a systematic review. Clin Orthop Relat Res 2013;471(01):264-276

13 Lonner JH, Kerr GJ. Robotically assisted unicompartmental knee arthroplasty. Oper Tech Orthop 2012;22:182-188

14 Citak M, Suero EM, Citak M, et al. Unicompartmental knee arthroplasty: is robotic technology more accurate than conventional technique? Knee 2013;20(04):268-271

15 Dunbar NJ, Roche MW, Park BH, Branch SH, Conditt MA, Banks SA. Accuracy of dynamic tactile-guided unicompartmental knee arthroplasty. J Arthroplasty 2012;27(05):803-8.e1

16 Plate JF, Mofidi A, Mannava S, et al. Achieving accurate ligament balancing using robotic-assisted unicompartmental knee arthroplasty. Adv Orthop 2013;2013:837167

17 Hampp EL, et al. Robotic-arm assisted total knee arthroplasty demonstrated greater accuracy and precision to plan compared with manual techniques. J Knee Surg 2019;32(03):239-250

18 Khlopas A, Chughtai M, Hampp EL, et al. Robotic-arm assisted total knee arthroplasty demonstrated soft tissue protection. Surg Technol Int 2017;30:441-446

19 Hampp EL, Sodhi N, Scholl L, et al. Less iatrogenic soft-tissue damage utilizing robotic-assisted total knee arthroplasty when compared with a manual approach: A blinded assessment. Bone Joint Res 2019;8(10):495-501

20 Khlopas A, Sodhi N, Hozack WJ, et al. Patient-reported functional and satisfaction outcomes after robotic-arm-assisted total knee arthroplasty: early results of a prospective multicenter investigation. J Knee Surg 2020;33(07):685-690

21 Khlopas A, Sodhi N, Sultan AA, Chughtai M, Molloy RM, Mont MA. Robotic arm-assisted total knee arthroplasty. J Arthroplasty 2018;33(07):2002-2006

22 Marchand RC, Sodhi N, Bhowmik-Stoker M, et al. Does the robotic arm and preoperative CT planning help with 3D intraoperative total knee arthroplasty planning? J Knee Surg 2019;32(08): 742-749

23 Marchand RC, Sodhi N, Khlopas A, et al. Patient satisfaction outcomes after robotic arm-assisted total knee arthroplasty: a short-term evaluation. J Knee Surg 2017;30(09):849-853

24 Malkani AL, Roche MW, Kolisek FR, et al. New technology for total knee arthroplasty provides excellent patient-reported outcomes: a minimum two-year analysis. Multicenter Study 2020;36:276-280

25 Malkani AL, Roche MW, Kolisek FR, et al. Manipulation under anesthesia rates in technology-assisted versus conventional-instrumentation total knee arthroplasty. Surg Technol Int 2019; 36:336-340

26 Matziolis G, Krocker D, Weiss U, Tohtz S, Perka C. A prospective, randomized study of computer-assisted and conventional total knee arthroplasty. Three-dimensional evaluation of implant alignment and rotation. J Bone Joint Surg Am 2007;89(02):236-243

27 Chauhan SK, Clark GW, Lloyd S, Scott RG, Breidahl W, Sikorski JM. Computer-assisted total knee replacement. A controlled cadaver study using a multi-parameter quantitative CT assessment of alignment (the Perth CT Protocol). J Bone Joint Surg Br 2004;86 (06):818-823

28 Noble PC, Scuderi GR, Brekke AC, et al. Development of a new Knee Society scoring system. Clin Orthop Relat Res 2012;470(01): 20-32

29 Scuderi GR, Bourne RB, Noble PC, Benjamin JB, Lonner JH, Scott WN. The new knee society knee scoring system. Clin Orthop Relat Res 2012;470(01):3-19

30 Iqbal SU, Rogers W, Selim A, et al. The Veterans RAND 12 Item Health Survey (VR-12): What it is and how it is used. Available at: http://www.hosonline.org/globalassets/hos-online/publications/ veterans_rand_12_item_health_survey_vr-12_2007.pdf. Accessed July 4, 2016

31 Kazis LE, Miller DR, Skinner KM, et al. Applications of methodologies of the Veterans Health Study in the VA healthcare system: conclusions and summary. J Ambul Care Manage 2006;29(02): 182-188

32 Ware J Jr, Kosinski M, Keller SDA. A 12-Item Short-Form Health Survey: construction of scales and preliminary tests of reliability and validity. Med Care 1996;34(03):220-233

33 Gornet MF, Copay AG, Sorensen KM, Schranck FW. Assessment of health-related quality of life in spine treatment: conversion from SF-36 to VR-12. Spine J 2018;18(07):1292-1297

34 Harris PA, Taylor R, Thielke R, Payne J, Gonzalez N, Conde JG. Research electronic data capture (REDCap)-a metadata-driven methodology and workflow process for providing translational research informatics support. J Biomed Inform 2009;42(02):377-381

35 Fleiss JL. Analysis of data from multiclinic trials. Control Clin Trials 1986;7(04):267-275

36 Katz JN, Wright EA, Guadagnoli E, Liang MH, Karlson EW, Cleary PD. Differences between men and women undergoing major orthopedic surgery for degenerative arthritis. Arthritis Rheum 1994;37(05):687-694

37 Marchand RC, Sodhi N, Anis HK, et al. One-year patient outcomes for robotic-arm-assisted versus manual total knee arthroplasty. J Knee Surg 2019;32(11):1063-1068

38 Sultan AA, Piuzzi N, Khlopas A, Chughtai M, Sodhi N, Mont MA. Utilization of robotic-arm assisted total knee arthroplasty for soft tissue protection. Expert Rev Med Devices 2017;14(12):925-927

39 Urish KL, Conditt M, Roche M, Rubash HE. Robotic total knee arthroplasty: surgical assistant for a customized normal kinematic knee. Orthopedics 2016;39(05):e822-e827

40 Nickel B, Carroll K, Pearle A, Kleeblad L, Mayman D, Jerabek S. Aim Small, Miss Small: Radiographic and Functional Outcomes of Robotic-Assisted Total Knee Arthroplasty at One Year. Eur Fed Orthop Traumatol Annual Congress. Lisbon, 2019

41 Parratte S, Price AJ, Jeys LM, Jackson WF, Clarke HD. Accuracy of a new robotically assisted technique for total knee arthroplasty: a cadaveric study. J Arthroplasty 2019;34(11):2799-2803

42 Jaramaz B, Mitra R, Nikou C, et al. Technique and accuracy assessment of a novel image-free handheld robot for knee arthroplasty in bi-cruciate retaining total knee replacement. EPIC Ser Health Sci 2018;2:98-101 